\title{
The land crab Johngarthia planata (Stimpson, 1860) (Crustacea, Brachyura, Gecarcinidae) colonizes human-dominated ecosystems in the continental mainland coast of Mexico
}

\author{
Robert Perger ${ }^{\dagger}$ \\ † Coleccion Boliviana de Fauna, La Paz, Bolivia
}

Corresponding author: Robert Perger (robertperger@hotmail.com)

Academic editor: Niamh Kilgallen

Received: 20 Jun 2014 | Accepted: 30 Jun 2014 | Published: 08 Jul 2014

Citation: Perger R (2014) The land crab Johngarthia planata (Stimpson, 1860) (Crustacea, Brachyura,

Gecarcinidae) colonizes human-dominated ecosystems in the continental mainland coast of Mexico. Biodiversity

Data Journal 2: e1161. doi: 10.3897/BDJ.2.e1161

\section{Abstract}

The land crab Johngarthia planata (Stimpson, 1860) has been reported from the Baja California Peninsula and several oceanic islands in the Eastern Pacific as well as inshore islands of the Mexican, Costa Rican and Colombian coast. However, the species has not been observed on the continental mainland, as it is likely that the high diversity of terrestrial predators/competitors make the establishment of mainland populations nearly impossible. In this contribution, several new records of this species that have been observed in urban areas along the continental Pacific coast of Mexico are reported. These records demonstrate that the presence of humans does not necessarily have a negative impact on land crab species. Indeed, the presence of humans may actually discourage the presence of native crab predators/competitors and hence increase the likelihood of a successful mainland settlement of land crab species that are otherwise island and peninsula restricted. The presence of $J$. planata is ecologically relevant for coastal forests because gecarcinid crabs significantly influence plant recruitment and $\mathrm{J}$. planata is considerably larger than the mainland species Gecarcinus quadratus. 


\section{Keywords}

Brachyura, dispersal, distribution, East Pacific, Mexico, new record

\section{Introduction}

Macroevolutionary transitions between marine and non-marine habitats are uncommon and rarely lead to long-term success in the invaded habitat (Vermeij and Dudley 2000). This is largely due to terrestrial niches being occupied by groups with a longer evolutionary history in these habitats as well as the marine invaders' lack of traits withwhich to successfully confront the differences in terrestrial selection regimes (Vermeij and Dudley 2000).

However, while their larvae still develop in marine habitats, adults of the crab family Gecarcinidae have successfully conquered island habitats, where they play an important ecological role (Lindquist et al. (2009) for a review). Species of the Gecarcinus-group (including Johngarthia, Gecarcinus and Gecarcoidea (Türkay 1987) are dominant through sheer numbers, on some islands their mass exceeds the total mass of animals reported in tropical rain forests in Costa Rica and the central Amazon (Lindquist et al. 2009) and they may occupy the top of the energy pyramid (Burggren and McMahon 1988).

Nevertheless, despite their success on islands and possible dispersal in their larval stage via sea currents, most species of the Gecarcinus-group are absent from continental mainland habitats (Türkay 1987; see Paulay and Starmer 2011). One reason for this may be the predictable mass migrations to the coast for larval release (e.g. Linnaeus 1758, Hicks 1985, Hartnoll 2011), which may render species of this group especially vulnerable to terrestrial predators, therefore limiting dispersion and the chances of success on the continental mainland. The negative impact on populations exerted by e.g. terrestrial vertebrates is supported by observed population declines or extinctions after island settlements by humans, which often actively hunt land crabs, or after the anthropogenic introduction of crab predators/competitors such as rats, feral cats and pigs (Paulay and Starmer 2011).

Johngarthia planata (Stimpson, 1860) appears to be a textbook example for the group's failure to establish itself on the continental mainland despite the advantages of ecological flexibility and favorable larval dispersion patterns (reviewed by Perger et al. 2013). Johngarthia planata occurs on the Baja California Peninsula and several oceanic islands in the Eastern Pacific as well as on inshore islands of the Mexican, Costa Rican and Colombian coasts. This wide presence is likely the result of amplified dispersal via coastal currents (Perger et al. 2013). However, likely due to the large diversity of terrestrial predators/competitors, J. planata has not been observed on continental mainland locations until now (Perger et al. 2013). 
In this study I report the first continental mainland records for J. planata and discuss the possibility that human presence might actually facilitate the mainland settlement of such a species.

\section{Materials and methods}

The present study encompasses the Pacific coast from Mexico to Colombia. Following Grismer (2000) and Riddle et al. (2000) the Baja California peninsula is treated separately to the rest of Mexico, which is referred to throughout the text as "Mexican mainland" or "continental mainland" respectively. To investigate the mainland presence/absence patterns of J. planata I performed an Internet search via Google.com (search function "images") and flickr.com. Flickr is an image hosting web site that is reported to host more than 6 billion photographs. Users uploading their photos to Flickr are able to add key words ("tags") that facilitate a search on Flickr and also in web search services such as Google and Yahoo. I searched with various combinations of the key words "crab" or "cangrejo" (Spanish for crab) and "Pacific, Mexico, Guatemala, El Salvador, Nicaragua, Costa Rica, Panama, Colombia"; and all regions of the respective countries with access to the Pacific coast. I then considered for evaluation only individuals on photographs from locations that were confirmed by the photographers and demonstrated clearly visible characteristics of $J$. planata (see Perger et al. 2013).

The following abbreviations are used in the text: LACM - Natural History Museum of Los Angeles County, Los Angeles, California; MNHN - Muséum National d'Histoire Naturelle, Paris, France; MZ-UCR - Museo de Zoología, Universidad de Costa Rica, San José, Costa Rica; USNM - National Museum of Natural History, Smithsonian Institution, Washington, D.C.

\section{Taxon treatment}

Johngarthia planata (Stimpson, 1860)

\section{Materials}

a. ScientificName: Johngarthia planata Stimpson, 1860; namePublishedln: Stimpson W (1860) Notes on North American Crustacea, in the museum of the Smithsonian Institution, No II. Annals of the Lyceum of Natural History of New York 7: 176-246.; order: Decapoda; family: Gecarcinidae; genus: Johngarthia; specificEpithet: planata; scientificNameAuthorship: W. Stimpson 1860; waterBody: East Pacific; island: Caño Island; country: Costa Rica; stateProvince: Puntarenas; verbatimLocality: Caño Island; verbatimElevation: $39 \mathrm{~m}$; decimalLatitude: 8.70861111111111 ; decimalLongitude: -83.88916666666667; samplingProtocol: manual search; samplingEffort: 2 hours; eventDate: 2011-02-25; individualCount: 2; sex: 1 male, 1 female; reproductiveCondition: egg-bearing female; behavior: running, agonistic display, pinching, producing bubbles in mouth area; recordedBy: Robert Perger; identificationID: Robert Perger 
b. ScientificName: Johngarthia planata Stimpson, 1860; namePublishedln: Stimpson W (1860) Notes on North American Crustacea, in the museum of the Smithsonian Institution, No II. Annals of the Lyceum of Natural History of New York 7: 176-246.; order: Decapoda; family: Gecarcinidae; genus: Johngarthia; specificEpithet: planata; scientificNameAuthorship: W. Stimpson 1860; waterBody: East Pacific; island: Nairita Island; country: Costa Rica; stateProvince: Puntarenas; verbatimLocality: Nairita Island; verbatimElevation: $1 \mathrm{~m}$; decimalLatitude: 8.67; decimalLongitude: -83.71777777777778; samplingProtocol: manual search; samplingEffort: 4 hours; eventDate: 2011-03-17; individualCount: 14; sex: juveniles; recordedBy: Robert Perger; identificationID: Robert Perger; institutionCode: MZ-UCR

C. ScientificName: Johngarthia planata Stimpson, 1860; namePublishedln: Stimpson W (1860) Notes on North American Crustacea, in the museum of the Smithsonian Institution, No II. Annals of the Lyceum of Natural History of New York 7: 176-246.; order: Decapoda; family: Gecarcinidae; genus: Johngarthia; specificEpithet: planata; scientificNameAuthorship: W. Stimpson 1860; waterBody: East Pacific; island: Colorada Island; country: Costa Rica; stateProvince: Guanacaste; verbatimLocality: Colorada Island; verbatimElevation: $13 \mathrm{~m}$; decimalLatitude: 10.846111111111112; decimalLongitude: -85.8611111111111; eventDate: 2000-10-20; individualCount: 2; sex: males; recordedBy: F. Joyce; identificationID: Robert Perger; institutionCode: MZ-UCR

d. scientificName: Johngarthia planata Stimpson, 1860; namePublishedln: Stimpson W (1860) Notes on North American Crustacea, in the museum of the Smithsonian Institution, No II. Annals of the Lyceum of Natural History of New York 7: 176-246.; order: Decapoda; family: Gecarcinidae; genus: Johngarthia; specificEpithet: planata; scientificNameAuthorship: W. Stimpson 1860; waterBody: East Pacific; island: Socorro Island; country: Mexico; verbatimLocality: Socorro Island; individualCount: 1; sex: male; recordedBy: A. Anthony; institutionCode: MNHN

e. scientificName: Johngarthia planata Stimpson, 1860; namePublishedln: Stimpson W (1860) Notes on North American Crustacea, in the museum of the Smithsonian Institution, No II. Annals of the Lyceum of Natural History of New York 7: 176-246.; order: Decapoda; family: Gecarcinidae; genus: Johngarthia; specificEpithet: planata; scientificNameAuthorship: W. Stimpson 1860; waterBody: East Pacific; island: Socorro Island; country: Mexico; verbatimLocality: Socorro Island; eventDate: 1971-02-16; individualCount: 2; sex: males; identificationID: John Garth; institutionCode: LACM f. ScientificName: Johngarthia planata Stimpson, 1860; namePublishedln: Stimpson W (1860) Notes on North American Crustacea, in the museum of the Smithsonian Institution, No II. Annals of the Lyceum of Natural History of New York 7: 176-246.; order: Decapoda; family: Gecarcinidae; genus: Johngarthia; specificEpithet: planata; scientificNameAuthorship: W. Stimpson 1860; waterBody: East Pacific; island: Socorro Island; country: Mexico; verbatimLocality: Socorro Island; individualCount: 1; sex: male; recordedBy: A. Anthony; institutionCode: USNM

g. scientificName: Johngarthia planata Stimpson, 1860; namePublishedln: Stimpson W (1860) Notes on North American Crustacea, in the museum of the Smithsonian Institution, No II. Annals of the Lyceum of Natural History of New York 7: 176-246.; order: Decapoda; family: Gecarcinidae; genus: Johngarthia; specificEpithet: planata; scientificNameAuthorship: W. Stimpson 1860; waterBody: East Pacific; island: San Benedicto Island; country: Mexico; verbatimLocality: San Benedicto Island; individualCount: 2; sex: males; identificationID: John Garth; institutionCode: LACM h. ScientificName: Johngarthia planata Stimpson, 1860; namePublishedln: Stimpson W (1860) Notes on North American Crustacea, in the museum of the Smithsonian Institution, No II. Annals of the Lyceum of Natural History of New York 7: 176-246.; order: Decapoda; 
family: Gecarcinidae; genus: Johngarthia; specificEpithet: planata; scientificNameAuthorship: W. Stimpson 1860; waterBody: East Pacific; island: San Benedicto Island; country: Mexico; verbatimLocality: San Benedicto Island; individualCount: 1; sex: male; recordedBy: A. Anthony; institutionCode: USNM

i. ScientificName: Johngarthia planata Stimpson, 1860; namePublishedln: Stimpson W (1860) Notes on North American Crustacea, in the museum of the Smithsonian Institution, No II. Annals of the Lyceum of Natural History of New York 7: 176-246.; order: Decapoda; family: Gecarcinidae; genus: Johngarthia; specificEpithet: planata; scientificNameAuthorship: W. Stimpson 1860; waterBody: East Pacific; country: Mexico; verbatimLocality: Baja California; individualCount: 1; sex: male; recordedBy: Léon Diguet; institutionCode: MNHN

j. ScientificName: Johngarthia planata Stimpson, 1860; namePublishedln: Stimpson W (1860) Notes on North American Crustacea, in the museum of the Smithsonian Institution, No II. Annals of the Lyceum of Natural History of New York 7: 176-246.; order: Decapoda; family: Gecarcinidae; genus: Johngarthia; specificEpithet: planata;

scientificNameAuthorship: W. Stimpson 1860; waterBody: East Pacific; country: Mexico; verbatimLocality: María Cleofas Island; eventDate: 1897-05-30; individualCount: 1; sex: male; recordedBy: Edward William Nelson; Edward Alphonso Goldman; institutionCode: USNM

k. scientificName: Johngarthia planata Stimpson, 1860; namePublishedln: Stimpson W (1860) Notes on North American Crustacea, in the museum of the Smithsonian Institution, No II. Annals of the Lyceum of Natural History of New York 7: 176-246.; order: Decapoda; family: Gecarcinidae; genus: Johngarthia; specificEpithet: planata; scientificNameAuthorship: W. Stimpson 1860; waterBody: East Pacific; country: France; verbatimLocality: Clipperton Island; eventDate: 1958-09-12; individualCount: 4; sex: males; recordedBy: Conrad Limbaugh; identificationID: John Garth; institutionCode: LACM

I. ScientificName: Johngarthia planata Stimpson, 1860; namePublishedln: Stimpson W (1860) Notes on North American Crustacea, in the museum of the Smithsonian Institution, No II. Annals of the Lyceum of Natural History of New York 7: 176-246.; order: Decapoda; family: Gecarcinidae; genus: Johngarthia; specificEpithet: planata; scientificNameAuthorship: W. Stimpson 1860; waterBody: East Pacific; country: France; verbatimLocality: Clipperton Island; individualCount: 1; sex: male; identificationID: Danièle Guinot; institutionCode: MNHN

m. ScientificName: Johngarthia planata Stimpson, 1860; namePublishedln: Stimpson W (1860) Notes on North American Crustacea, in the museum of the Smithsonian Institution, No II. Annals of the Lyceum of Natural History of New York 7: 176-246.; order: Decapoda; family: Gecarcinidae; genus: Johngarthia; specificEpithet: planata; scientificNameAuthorship: W. Stimpson 1860; waterBody: East Pacific; country: France; verbatimLocality: Clipperton Island; individualCount: 2; sex: 1 male, 1 female; recordedBy: J. Arnheim; institutionCode: USNM

n. ScientificName: Johngarthia planata Stimpson, 1860; namePublishedln: Stimpson W (1860) Notes on North American Crustacea, in the museum of the Smithsonian Institution, No II. Annals of the Lyceum of Natural History of New York 7: 176-246.; order: Decapoda; family: Gecarcinidae; genus: Johngarthia; specificEpithet: planata; scientificNameAuthorship: W. Stimpson 1860; waterBody: East Pacific; country: Panama; verbatimLocality: Iguana Island; year: 2006; habitat: beach; individualCount: 1; sex: female; recordedBy: María Elena Valencia; identificationID: Robert Perger; type: Photograph; rightsHolder: María Elena Valencia 
o. ScientificName: Johngarthia planata Stimpson, 1860; namePublishedln: Stimpson W (1860) Notes on North American Crustacea, in the museum of the Smithsonian Institution, No II. Annals of the Lyceum of Natural History of New York 7: 176-246.; order: Decapoda; family: Gecarcinidae; genus: Johngarthia; specificEpithet: planata; scientificNameAuthorship: W. Stimpson 1860; waterBody: East Pacific; country: Panama; verbatimLocality: Iguana Island; year: 2013; habitat: beach; individualCount: 1; sex: juvenile; recordedBy: Julio Larish; identificationID: Robert Perger; type: Photograph; rightsHolder: Julio Larish

p. scientificName: Johngarthia planata Stimpson, 1860; namePublishedln: Stimpson W (1860) Notes on North American Crustacea, in the museum of the Smithsonian Institution, No II. Annals of the Lyceum of Natural History of New York 7: 176-246.; order: Decapoda; family: Gecarcinidae; genus: Johngarthia; specificEpithet: planata; scientificNameAuthorship: W. Stimpson 1860; waterBody: East Pacific; country: Mexico; stateProvince: Sinaloa; verbatimLocality: Mazatlán; year: 2008; habitat: beach; individualCount: 1; recordedBy: Lisa Brettschneider; identificationID: Robert Perger; type: Photograph; rightsHolder: Lisa Brettschneider

q. $\quad$ scientificName: Johngarthia planata Stimpson, 1860; namePublishedln: Stimpson W (1860) Notes on North American Crustacea, in the museum of the Smithsonian Institution, No II. Annals of the Lyceum of Natural History of New York 7: 176-246.; order: Decapoda; family: Gecarcinidae; genus: Johngarthia; specificEpithet: planata; scientificNameAuthorship: W. Stimpson 1860; waterBody: East Pacific; country: Mexico; stateProvince: Nayarit; verbatimLocality: Sayulita; year: 2005; habitat: beach; individualCount: 1; recordedBy: Lisa Johnston; identificationID: Robert Perger; type: Photograph; rightsHolder: Lisa Johnston

r. ScientificName: Johngarthia planata Stimpson, 1860; namePublishedln: Stimpson W (1860) Notes on North American Crustacea, in the museum of the Smithsonian Institution, No II. Annals of the Lyceum of Natural History of New York 7: 176-246.; order: Decapoda; family: Gecarcinidae; genus: Johngarthia; specificEpithet: planata;

scientificNameAuthorship: W. Stimpson 1860; waterBody: East Pacific; country: Mexico; stateProvince: Nayarit; verbatimLocality: Sayulita; year: 2007; habitat: on roof of house; individualCount: 1; recordedBy: Tania Beagley-Brown; identificationID: Robert Perger; type: Photograph; rightsHolder: Tania Beagley-Brown

S. ScientificName: Johngarthia planata Stimpson, 1860; namePublishedln: Stimpson W (1860) Notes on North American Crustacea, in the museum of the Smithsonian Institution, No II. Annals of the Lyceum of Natural History of New York 7: 176-246.; order: Decapoda; family: Gecarcinidae; genus: Johngarthia; specificEpithet: planata;

scientificNameAuthorship: W. Stimpson 1860; waterBody: East Pacific; country: Mexico; stateProvince: Nayarit; verbatimLocality: Sayulita; year: 2010; habitat: beach; individualCount: 2; sex: 1 male, 1 female; recordedBy: Daniel Brewer; identificationID: Robert Perger; type: Photograph; rightsHolder: Daniel Brewer

t. ScientificName: Johngarthia planata Stimpson, 1860; namePublishedln: Stimpson W (1860) Notes on North American Crustacea, in the museum of the Smithsonian Institution, No II. Annals of the Lyceum of Natural History of New York 7: 176-246.; order: Decapoda; family: Gecarcinidae; genus: Johngarthia; specificEpithet: planata; scientificNameAuthorship: W. Stimpson 1860; waterBody: East Pacific; country: Mexico; stateProvince: Nayarit; verbatimLocality: Sayulita; year: 2010; habitat: beach; individualCount: 2; sex: 1 male, 1 female; recordedBy: Daniel Brewer; identificationID: Robert Perger; type: Photograph; rightsHolder: Daniel Brewer

u. ScientificName: Johngarthia planata Stimpson, 1860; namePublishedln: Stimpson W (1860) Notes on North American Crustacea, in the museum of the Smithsonian Institution, 
No II. Annals of the Lyceum of Natural History of New York 7: 176-246.; order: Decapoda; family: Gecarcinidae; genus: Johngarthia; specificEpithet: planata; scientificNameAuthorship: W. Stimpson 1860; waterBody: East Pacific; country: Mexico; stateProvince: Nayarit; verbatimLocality: Sayulita; year: 2013; habitat: beach; individualCount: 1; sex: male; recordedBy: Madeline Milne; identificationID: Robert Perger; type: Photograph; rightsHolder: Madeline Milne

v. scientificName: Johngarthia planata Stimpson, 1860; namePublishedln: Stimpson W (1860) Notes on North American Crustacea, in the museum of the Smithsonian Institution, No II. Annals of the Lyceum of Natural History of New York 7: 176-246.; order: Decapoda; family: Gecarcinidae; genus: Johngarthia; specificEpithet: planata;

scientificNameAuthorship: W. Stimpson 1860; waterBody: East Pacific; country: Mexico; stateProvince: Jalisco; verbatimLocality: Mismaloya; year: 2007; habitat: beach; individualCount: 1; recordedBy: Darin Williams; identificationID: Robert Perger; type: Photograph; rightsHolder: Darin Williams

w. ScientificName: Johngarthia planata Stimpson, 1860; namePublishedln: Stimpson W (1860) Notes on North American Crustacea, in the museum of the Smithsonian Institution, No II. Annals of the Lyceum of Natural History of New York 7: 176-246.; order: Decapoda; family: Gecarcinidae; genus: Johngarthia; specificEpithet: planata;

scientificNameAuthorship: W. Stimpson 1860; waterBody: East Pacific; country: Mexico; stateProvince: Colima; verbatimLocality: Manzanillo; year: 2004; habitat: beach; individualCount: 1; recordedBy: Derek Zoebelein; identificationID: Robert Perger; type: Photograph; rightsHolder: Derek Zoebelein

X. ScientificName: Johngarthia planata Stimpson, 1860; namePublishedln: Stimpson W (1860) Notes on North American Crustacea, in the museum of the Smithsonian Institution, No II. Annals of the Lyceum of Natural History of New York 7: 176-246.; order: Decapoda; family: Gecarcinidae; genus: Johngarthia; specificEpithet: planata; scientificNameAuthorship: W. Stimpson 1860; waterBody: East Pacific; country: Mexico; stateProvince: Guerrero; verbatimLocality: Ixtapa; year: 2012; habitat: beach; individualCount: 1; sex: male; recordedBy: Miguel Angel Morales; identificationID: Robert Perger; type: Photograph; rightsHolder: Miguel Angel Morales

y. ScientificName: Johngarthia planata Stimpson, 1860; namePublishedln: Stimpson W (1860) Notes on North American Crustacea, in the museum of the Smithsonian Institution, No II. Annals of the Lyceum of Natural History of New York 7: 176-246.; order: Decapoda; family: Gecarcinidae; genus: Johngarthia; specificEpithet: planata;

scientificNameAuthorship: W. Stimpson 1860; waterBody: East Pacific; country: Mexico; stateProvince: Oaxaca; verbatimLocality: Mazunte; year: 2008; habitat: beach; individualCount: 1; sex: male; recordedBy: Gustavo A. Zambrano Cabrera; identificationID: Robert Perger; type: Photograph; rightsHolder: Gustavo A. Zambrano Cabrera

z. ScientificName: Johngarthia planata Stimpson, 1860; namePublishedln: Stimpson W (1860) Notes on North American Crustacea, in the museum of the Smithsonian Institution, No II. Annals of the Lyceum of Natural History of New York 7: 176-246.; order: Decapoda; family: Gecarcinidae; genus: Johngarthia; specificEpithet: planata; scientificNameAuthorship: W. Stimpson 1860; waterBody: East Pacific; country: Mexico; stateProvince: Oaxaca; verbatimLocality: Escondido Beach; year: 2010; habitat: beach; individualCount: 1; sex: male; recordedBy: Mike Gardiner; identificationID: Robert Perger; type: Photograph; rightsHolder: Mike Gardiner

aa. scientificName: Johngarthia planata Stimpson, 1860; namePublishedln: Stimpson W (1860) Notes on North American Crustacea, in the museum of the Smithsonian Institution, No II. Annals of the Lyceum of Natural History of New York 7: 176-246.; order: Decapoda; 
family: Gecarcinidae; genus: Johngarthia; specificEpithet: planata;

scientificNameAuthorship: W. Stimpson 1860; waterBody: East Pacific; country: Mexico; stateProvince: Oaxaca; verbatimLocality: Zapotengo Beach; year: 2011; habitat: beach; individualCount: 1; sex: juvenile; recordedBy: Claudia Glechner; identificationID: Robert Perger; type: Photograph; rightsHolder: Claudia Glechner

\section{Analysis}

The Internet search revealed photographs of 12 individuals from Mexico (mainland) and three individuals from Panama (Iguana Island) (Table 1, Figs 1, 2). The diagnostic characters used (both apical lobes of the third maxilliped merus subequal, the leg spines prominently developed, the carapace depressed and the dark red color with orange chelipeds and cream cutting edges) (Fig. 1) were consistent with other examined specimens found on islands in Mexico and Costa Rica (Perger et al. 2013) as well as on Gorgona Island, Colombia (see Shih 2013). The specimens found on the Mexican mainland are the first continental mainland specimens ever recorded, and the specimens on Iguana Island are the first recorded in Panama. The species has been previously reported by Bright and Hogue (1972) and Jiménez et al. (1994) for "Panama" in error, likely following the reference "Malpelo Island, off Bay of Panama" by Rathbun (1918). Malpelo Island is inhabited by J. malpilensis, but the island is part of Colombia.

\section{Table 1.}

Island and mainland records for Johngarthia planata obtained from the literature (L) and photographs $(\mathrm{P})$; new records highlighted by $\left(^{*}\right)$.

\begin{tabular}{|l|l|}
\hline Location & Source \\
\hline Colombia & \\
\hline Gorgona Island & Prahl 1983 (L) \\
\hline Costa Rica & \\
\hline Colorada Island & Perger et al. 2013 (L) \\
\hline Caño Island & Perger et al. 2013 (L) \\
\hline Nairita Island & Perger et al. 2013 (L) \\
\hline Panama & \\
\hline Iguana Island* & María Elena Valencia 2006; Julio Larish 2013 (P) \\
\hline Mexico, islands & \\
\hline Clipperton Island & Lenz 1901, Rathbun 1918, Garth 1965 (L) \\
\hline Pájaros Island, Michoacán & García-Madrigal 2000 (L) \\
\hline Isabela Island, Nayarit & Rathbun 1899 (L) \\
\hline Maria Cleofa Island, Nayarit & Rathbun 1899 (L) \\
\hline Pájaros Island, Sinaloa & Arzola-González et al. 2010 (L) \\
\hline San Pedro Nolasco Island, Gulf of California & Felger et al. 2011 (L) \\
\hline
\end{tabular}




\begin{tabular}{|l|l|}
\hline Socorro Island & Rodriguez et al. 1996, Ortega-Rubio et al. 1997 (L) \\
\hline San Benedicto Island & Brattstrom and Howell 1956 (L) \\
\hline Clarion Island & Hernández-Aguilera et al. 1986 (L) \\
\hline Bacochibampo Bay, Sonora (small reef) & Manrique 1981 (L) \\
\hline Mexico, Baja California Peninsula & \\
\hline Cabo San Lucas & Stimpson 1860 (L) \\
\hline Mexico, mainland & \\
\hline Mazatlán, Sinaloa* & Lisa Brettschneider 2008 (P) \\
\hline Sayulita, Nayarit* & $\begin{array}{l}\text { Lisa Johnston 2005; Tania Beagley-Brown 2007; Daniel Brewer } \\
\text { 2010; Madeline Milne 2013 (P) }\end{array}$ \\
\hline Mismaloya, Jalisco* & Darin Williams 2007 (P) \\
\hline Manzanillo, Colima* & Derek Zoebelein 2004 (P) \\
\hline Ixtapa, Guerrero* & Miguel Angel Morales 2012 (P) \\
\hline Mazunte, Oaxaca * & Gustavo A. Zambrano Cabrera 2008 (P) \\
\hline Escondido Beach, Oaxaca* & Mike Gardiner 2010 (P) \\
\hline Zapotengo Beach, Oaxaca* & Claudia Glechner 2011 (P) \\
\hline
\end{tabular}

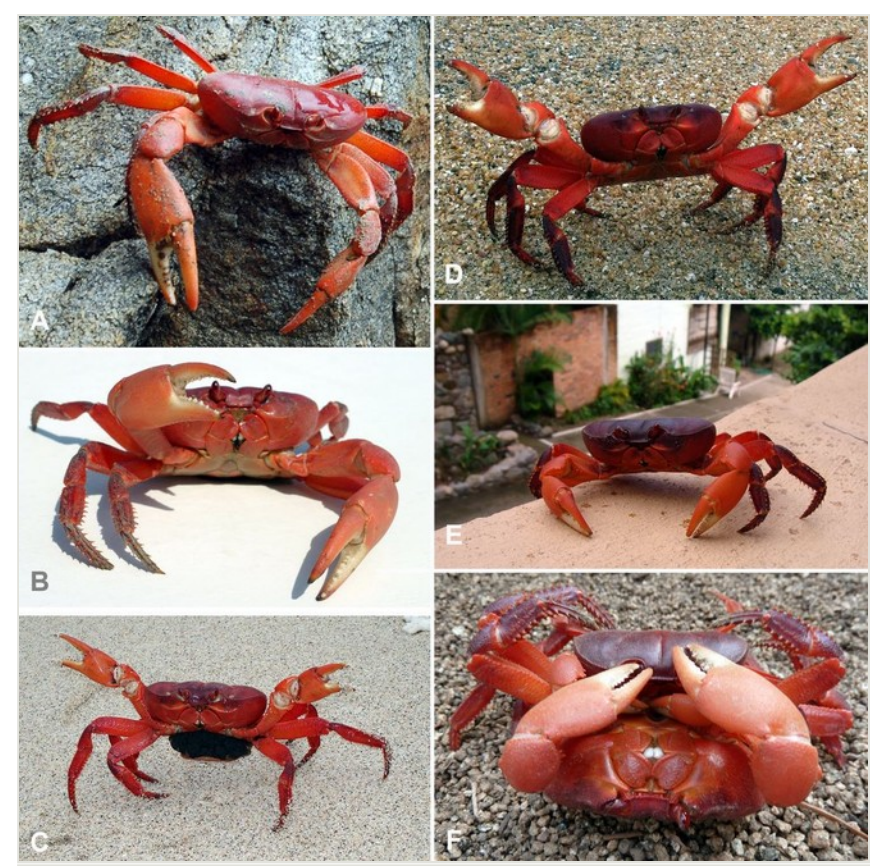

Figure 1.

Johngarthia planata (Stimpson, 1860) from continental mainland of Mexico and Iguana Island, Panama. A, Mexico, Oaxaca, Escondido Beach (photo by Mike Gardiner, 2010); B, Mexico, Colima, Manzanillo (photo by Derek Zoebelein, 2004); C, Panama, Iguana Island (photo by María Elena Valencia, 2006); D-E, Mexico, Nayarit, Sayulita (photos by Madeline Milne, 2013; Tania BeagleyBrown, 2007; and Daniel Brewer, 2011, respectively). 


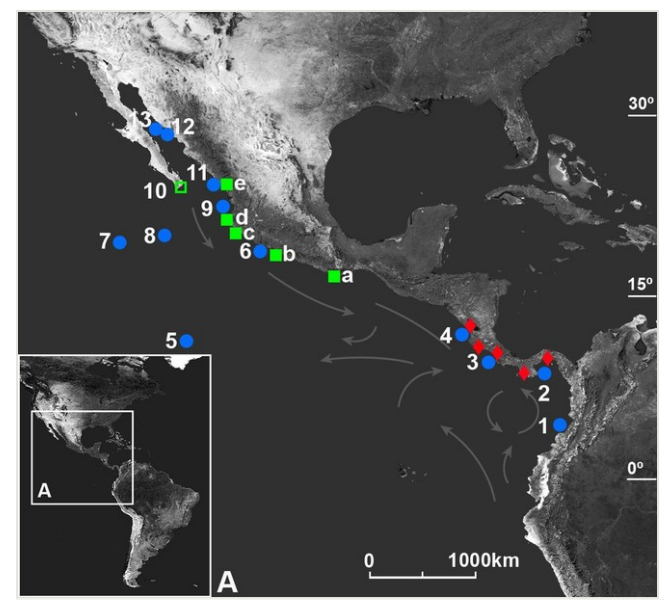

Figure 2.

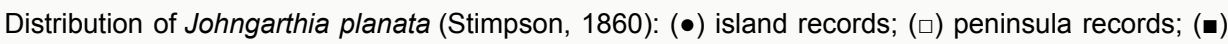
mainland records; $(\bullet)$ locations with confirmed mainland absence of J. planata (Perger et al. 2013; Perger unpubl. data). Colombia: (1) Gorgona Island. Panama: (2) Iguana Island. Costa Rica: (3) Caño and Nairita Islands; (4) Colorada Island. Mexico: (5) Clipperton Island; (6) Michoacán, Pajaro Island; (7) Clarion Island; (8) Socorro and San Benedicto Islands; (9) Maria Cleofa and Isabela Islands; (10) Baja California Peninsula, Cabo San Lucas; (11) Sinaloa, Pajaro Island; (12) Sonora, Bacochibampo Bay; (13) Gulf of California, San Pedro Nolasco Island; (a) Escondido, Mazunte, and Zapotengo Beach, Oaxaca; (b) Ixtapa, Guerrero; (c) Manzanillo, Colima; (d) Sayulita, Nayarit; Mismaloya, Jalisco; (e) Mazatlán, Sinaloa. Major sea currents indicated by arrows (modified after Kessler 2006).

All mainland records of $J$. planata cited here refer to tourist beaches close to villages or small cities. Several photographs show individuals of $J$. planata foraging diurnally, running along house walls or even inside of houses and mating (Fig. 1).

The Internet search did not reveal any photographs of $J$. planata from Guatemala, El Salvador, Nicaragua and Costa Rica. For the latter country, the only known records to date are those cited by Perger et al. (2013).

\section{Discussion}

Paulay and Starmer (2011) attribute the absence of land crab species on the continental mainland to the presence of predators. However, this pattern is less pronounced in the Neotropics where Cardisoma crassum, C. guanhumi, Gecarcinus lateralis and G. quadratus share evolutionary traits which allow it to adapt to the conditions in a coastal band of the continental mainland (e.g. Bright 1966, Sherman 2002, Lindquist et al. 2009). On the other hand, the remaining four species of Johngarthia (see López-Victoria and Werding 2008, Hartnoll 2010, Perger et al. 2011) and Gecarcinus ruricola (Bright and Hogue 1972) have been reported from islands only, supporting the pattern suggested by Paulay and Starmer (2011). Several studies strongly indicate that J. planata has not 
established populations along the Central American mainland coast (see Perger et al. 2013 for a short review; Fig. 2), which agrees with the pattern of mainland absence observed in the four congeners. The ecological flexibility of $\mathrm{J}$. planata, which occurs in habitats ranging from island rainforests to rocky terrain with sparse vegetation (Pérez-Chi 2005, Perger et al. 2013), suggest that the most significant factors which preclude such species from inhabiting the mainland are indeed competition or/and predation (Perger et al. 2013). The presence/absence pattern of $J$. planata in continental mainland habitats roughly coincides with the replacement of the moist forests of Panama and Costa Rica by dry forests that extend from Nicaragua to Mexico (see Ricketts et al. 1999). The diversity of possible crab predators such as birds (Orme et al. 2005) and mammals (Ceballos and Ehrlich 2006) is lower in the Southern Pacific Dry forest ecoregion than in tropical rainforests of Central America. Whether J. planata appears as well in non-urban areas along the Mexican Pacific coast remains unclear, however, the mainland establishment of such species might be facilitated close to or in urban areas where the lower diversity or/ and abundance of possible predators/competitors is influenced by the presence of humans. Studies from undisturbed forest in the Pacific coast of Costa Rica (Sherman 2002, Griffiths et al. 2007, pers. observ.) relate cryptic behavior of gecarcinid land crabs to less suitable abiotic conditions and predator presence. On Caño and Nairita (Perger et al. 2013), Maria Cleofa (Rathbun 1899), Socorro (Pérez-Chi 2005) and Gorgona (LópezVictoria and Werding 2008) islands, J. planata is active at night, which is most likely due to the presence of bird predators. In contrast, observations from Sayulita (Jolley and Brewer 2010), a newly reported mainland record for J. planata (Table 1; Fig. 1), suggest that the land crab activity there is less influenced by predator impact:

"Visitors who arrive in Sayulita during the rainy season (June-October) and decide to take a leisurely walk through the jungle towards the beach are usually quite surprised, even shocked, to find the jungle floor literally teeming with thousands of purple-and-yellow and red land crabs. Crabs seem to be foraging everywhere in the leaf litter, wildly waving their claws and scurrying away to their burrows and caves at the first apprehension of danger. Most people find them interesting and amusing, even comical, with their tubular, hypervigilant eyes, their defensive postures and wild gestures."

Further photographs and accounts by Jolley and Brewer (2010) and Brewer (in litt.) indicate that $J$. planata is a common element of the urban wildlife and seeks food and shelter in closest proximity to human houses:

"People who have built homes in the jungle near the ocean, however, consider the allpervasive land crabs quite troublesome. If the crabs can get into the house (they can climb walls!), they can damage clothing, books, and food. Outside of the house, they are quite hard on garden plants, shredding foliage and damaging plant roots from inside their tunnels. By the time November comes, most folks are happy to see the crabs retreat into the ground!" (Jolley and Brewer 2010)

These observations demonstrate that human presence does not necessarily have a negative impact on land crabs, as suggested by Paulay and Starmer (2011). The relationship between land crabs and humans might depend on the type of habitat, human 
settlement system and land use. Exploitation by hunter-gatherers on islands and the introduction of domesticated animals are assumed to have resulted in the extinction of local populations of G. ruricola (Pregill et al. 1988) and a species of Geograpsus (Paulay and Starmer 2011). However, the consumption of land crabs has not been reported from tourist destinations along the Neotropical Pacific coast. As free-roaming domestic animals may be seen as a detriment to tourism (Webster 2013), populations of possible land crab predators/competitors such as pigs, cats, dogs and rats (see Paulay and Starmer 2011) tend to be more controlled than in areas with farmers or hunter-gatherers.

Because gecarcinid land crabs significantly influence tree recruitment by consuming seeds, propagules and seedlings, they are considered important ecosystem engineers (reviewed by Lindquist et al. 2009). While human presence might open a new evolutionary pathway for these otherwise island restricted land crabs, the colonization of continental mainland forests by a large species such as J. planata (see López-Victoria and Werding (2008) for a size comparison) would certainly have profound consequences for the structure and species composition of coastal ecosystems, particularly in view of the possibility that their foraging activity would be less restricted due to lower predation pressure. Further surveys for J. planata and possible crab predators/competitors are needed to determine if the known distributional pattern of such species is the result of human influence.

\section{Acknowledgements}

Thanks are extended to Daniel Brewer, María Elena Valencia, Tania Beagley-Brown, Derek Zoebelein and Mike Gardiner for granting permission to publish their excellent photographs of Johngarthia planata and to Daniel Brewer for providing useful information on J. planata in Sayulita. I also thank Hsi-Te Shih (Department of Life Science, National Chung Hsing University, Taiwan) for making available a copy of Manrique (1981), and Richard Hartnoll (School of Biological Sciences, University of Liverpool), David Wilcox (USA), Lyubomir Penev (Bulgarian Academy of Science, Sofia), Niamh Kilgallen (Australian Museum, Sydney) and the anonymous reviewer for providing suggestions on an earlier draft of this manuscript.

\section{References}

- $\quad$ Arzola-González JF, Flores-Campaña LM, Vázquez-Cervantes A (2010) Crustáceos decápodos intermareales de las islas de la costa de Sinaloa, México. Universidad y ciencia 26 (2): 179-193.

- Brattstrom B, Howell T (1956) The Birds of the Revilla Gigedo Islands, Mexico. The Condor 58 (2): 107-120. DOI: 10.2307/1364977

- Bright DB (1966) The land crabs of Costa Rica. Revista de Biología Tropical 14: 183-203.

- $\quad$ Bright DB, Hogue CL (1972) A synopsis of the burrowing land crabs of the world and list of their arthropod symbionts and burrow associates. Natural History Museum of Los Angeles County, Contributions in Science 220: 1-58. 
- $\quad$ Burggren W, McMahon B (1988) Biology of the land crabs: An Introduction. Biology of the Land Crabs. DOI: $10.1017 /$ cbo9780511753428.002

- Ceballos G, Ehrlich PR (2006) Global mammal distributions, biodiversity hotspots, and conservation. Proceedings of the National Academy of Sciences 103 (51):

19374-19379. DOI: $10.1073 /$ pnas.0609334103

- $\quad$ Felger RS, Wilder BT, Gallo-Reynoso JP (2011) Floristic diversity and long-term vegetation dynamics of Isla San Pedro Nolasco, Gulf of California, Mexico. Proceedings of the San Diego Society of Natural History 43: 1-42.

- García-Madrigal MS (2000) Cangrejos Braquiuros (Brachyura) de la bahía de Maruata, Michoacán, México. Revista de Biología Tropical 48 (1): 181-191.

- Garth JS (1965) The brachyuran decapod crustaceans of Clipperton Island.

Proceedings of the California Academy of Sciences 33: 1-46.

- Griffiths ME, Mohammad BA, Vega A (2007) Dry season distribution of land crabs, Gecarcinus quadratus (Crustacea: Gecarcinidae), in Corcovado National Park, Costa Rica. Revista de biología tropical 55 (1): 219-224.

- Grismer LL (2000) Evolutionary biogeography on Mexico's Baja California peninsula: A synthesis of molecules and historical geology. Proceedings of the National Academy of Sciences 97 (26): 14017-14018. DOI: 10.1073/pnas.260509697

- Hartnoll RG (2010) Chastity belts and planktotrophic larvae: constraints on gecarcinid reproductive behaviour. In: Castro P, Davie JF, Ng PKL, Forges BRD (Eds) Studies on Brachyura: a homage to Danièle Guinot. 11. Crustaceana Monographs

- Hartnoll RG (2011) Ascension Island: contrasting biogeography of land and rock crabs. 9 Colloquium Crustacea Mediterranea, Torino, Sept. 2-6, Museo Regionali di Scienze naturali, Torino 2008: 375-385.

- Hernández-Aguilera JL, López-Salgado I, Sosa-Hernández P (1986) Fauna carcinológica insular de México I. Crustáceos estomatópodos y decápodos de la Isla Clarión. Secretaría de Marina, Dirección General de Oceanografía Naval, Investigaciones Oceanográficas 3: 183-250.

- Hicks J (1985) The Breeding Behaviour and Migrations of the Terrestrial Crab Gecarcoidea natalis (Decapoda: Brachyura). Australian Journal of Zoology 33 (2): 127-142. DOI: 10.1071/zo9850127

- Jiménez C, Ortega A, Alvarez S, Arnaud G (1994) Ecological aspects of the land crab Gecarcinus planatus (Decapoda: Gecarcinidae) in Socorro Island, Mexico. Biological Conservation 69 (1): 9-13. DOI: 10.1016/0006-3207(94)90323-9

- Jolley O, Brewer D (2010) Land crabs in Sayulita. URL: http://www.elsayulero.com/ story/land-crabs-sayulita

- Kessler W (2006) The circulation of the eastern tropical Pacific: A review. Progress in Oceanography 69: 181-217. DOI: 10.1016/j.pocean.2006.03.009

- Lenz H (1901) Ergebnisse einer Reise nach dem Pacific (Schauinsland 1896-1897). Crustaceen. Zoologische Jahrbücher 14: 429-482.

- $\quad$ Lindquist ES, Krauss KW, Green PT, O'Dowd DJ, Sherman PM, Smith TJ (2009) Land crabs as key drivers in tropical coastal forest recruitment. Biological Reviews 84 (2): 203-223. DOI: 10.1111/j.1469-185x.2008.00070.x

- Linnaeus C (1758) Systema naturae per regna tria naturae, secundum classes, ordines, genera, species, cum characteribus, differentiis, synonymis, locis. Holmiae, 824 pp.

- López-Victoria M, Werding B (2008) Ecology of the endemic land crab Johngarthia malpilensis (Decapoda: Brachyura: Gecarcinidae), a poorly known species from the 
Tropical Eastern Pacific. Pacific Science 62 (4): 483-493. DOI: 10.2984/1534-6188 (2008)62[483:eotelc]2.0.co;2

- $\quad$ Manrique F (1981) Two New Records for Land Crabs in the Gulf of California (Brachyura, Gecarcinidae). Crustaceana 41 (2): 216-217. DOI:

10.1163/156854081x00264

- $\quad$ Orme D, Davies R, Burgess M, Eigenbrod F, Pickup N, Olson V, Webster A, Ding S, Rasmussen P, Ridgely R, Stattersfield A, Bennett P, Blackburn T, Gaston K, Owens IF (2005) Global hotspots of species richness are not congruent with endemism or threat. Nature 436 (7053): 1016-1019. DOI: 10.1038/nature03850

- Ortega-Rubio A, Jiménez M, Llinas J, Arnaud G (1997) Some Ecological Aspects of the land crab Gecarcinus planatus, Stimpson, at Socorro Island, Colima, Mexico. of the Arizona-Nevado Acaderny of Sciences 30 (1): 17-22.

- Paulay G, Starmer J (2011) Evolution, Insular Restriction, and Extinction of Oceanic Land Crabs, Exemplified by the Loss of an Endemic Geograpsus in the Hawaiian Islands. PLoS ONE 6 (5): e19916. DOI: 10.1371/journal.pone.0019916

- Pérez-Chi A (2005) Densities, diel activity, burrow shape, and habitat characteristics of Gecarcinus (Johngarthia) planatus Stimpson, 1860 (Decapoda, Brachyura,

Gecarcinidae) at Socorro Island, Revillagigedo, Mexico. Crustaceana 78 (3): 255-272. DOI: $\underline{10.1163 / 1568540054286510}$

- Perger R, Cortes J, Pacheco C (2013) Closing a distributional gap of over $3000 \mathrm{~km}$ and encountering an invisible barrier: new presence/absence data for Johngarthia planata Stimpson, 1860 (Decapoda, Brachyura, Gecarcinidae) for Central America and biogeographic notes on East Pacific Gecarcinidae. Crustaceana 86 (3): 268-277. DOI: 10.1163/15685403-00003172

- $\quad$ Perger R, Vargas R, Wall A (2011) Johngarthia cocoensis, a new species of Gecarcinidae MacLeay, 1838 (Crustacea, Decapoda, Brachyura) from Cocos Island, Costa Rica. Zootaxa 2911: 57-68. URL: http://zoobank.org/21219256-69E1-4308B12E-4700D2B18266

- $\quad$ Prahl H (1983) Primer registro de Gecarcinus (Johngarthia) planatus Stimpson, 1860 (Crustacea: Gecarcinidae) para Colombia y notas sobre su zoogeografía en el Pacífico Americano. Anales del Instituto de Investigaciones Marinas de Punta de Betín 13: 143-148.

- $\quad$ Pregill GK, Steadman DW, Olson SL, Grady FV (1988) Late Holocene fossil vertebrates from Burma Quarry, Antigua, Lesser Antilles. Smithsonian Contributions to Zoology 463: 1-27.

- Rathbun MJ (1899) Notes on the Crustacea of the Tres Marias Islands. North American Fauna 14: 73-75. DOI: 10.3996/nafa. 14.0005

- Rathbun MJ (1918) The grapsoid crabs of America. Bulletin of the United States National Museum 97: 1-461. DOI: 10.5479/si.03629236.97.i

- $\quad$ Ricketts TH, Dinerstein E, Olson DM, Loucks CJ, Eichbaum W, Della-Sala D, Kavanagh K, Hedao P, Hurley PT, Carney KM, Abell R, Walters S (1999) Terrestrial ecoregions of North America: a conservation assessment. Island Press, Washington, D.C., USA, 485 pp.

- $\quad$ Riddle BR, Hafner DJ, Alexander LF, Jaeger JR (2000) Cryptic vicariance in the historical assembly of a Baja California Peninsular Desert biota. Proceedings of the National Academy of Sciences 97 (26): 14438-14443. DOI: 10.1073/pnas.250413397 
- Rodriguez R, Leon JL, Breceda A, Castellanos A, Cancino J, Llinas J (1996) Status, density and habitat relationships of the endemic terrestrial birds of Socorro Island, Revillagigedo Islands, Mexico. Biological Conservation 76 (2): 195-202. DOI: 10.1016/0006-3207(95)00104-2

- Sherman PM (2002) Effects of land crabs on seedling densities and distributions in a mainland neotropical rain forest. Journal of Tropical Ecology 18 (1): 67-89. DOI: $10.1017 / \mathrm{s} 0266467402002043$

- Shih HT (2013) Introduction of the gecarcinid land crabs of the world. Taiwan Natural Science 119: 22-37.

- Stimpson W (1860) Notes on North American Crustacea, in the museum of the Smithsonian Institution, No II. Annals of the Lyceum of Natural History of New York 7: 176-246.

- $\quad$ Türkay M (1987) Landkrabben. Natur und Museum 117 (5): 143-150.

- Vermeij G, Dudley R (2000) Why are there so few evolutionary transitions between aquatic and terrestrial ecosystems? Biological Journal of the Linnean Society 70 (4): 541-554. DOI: 10.1111/j.1095-8312.2000.tb00216.x

- Webster D (2013) The Economic Impact of Stray Cats and Dogs at Tourist Destinations on the Tourism Industry. Report CANDI International. URL: http:// www.humaneadvisor.com/wp-content/uploads/2013/05/Click-here-for-the-full-report.pdf 